\title{
Phylogeny and Expression of NADPH Oxidases during Symbiotic Nodule Formation
}

\author{
Jesús Montiel ${ }^{1} \mathbb{D}$, Citlali Fonseca-García ${ }^{2}$ and Carmen Quinto ${ }^{2, *}$ \\ 1 Department of Molecular Biology and Genetics, Aarhus University, Aarhus C 8000, Denmark; \\ jesusmg@mbg.au.dk \\ 2 Departamento de Biología Molecular de Plantas, Instituto de Biotecnología, Universidad Nacional \\ Autónoma de México, UNAM, Cuernavaca 62271, Morelos, Mexico; fonsecac@ibt.unam.mx \\ * Correspondence: quinto@ibt.unam.mx; Tel.: +52-777-329-1642
}

Received: 30 October 2018; Accepted: 14 November 2018; Published: 16 November 2018

\begin{abstract}
The mutualistic interaction between gram-negative soil bacteria and the roots of legumes leads to the establishment of nodules, where atmospheric nitrogen is fixed. Nodulation is a multistep process with numerous essential players. Among these are reactive oxygen species (ROS), which are mainly generated by Nicotinamide Adenine Dinucleotide Phosphate (NADPH) oxidases. In plants, these enzymes are known as respiratory burst oxidase homologs (RBOHs). In legumes, these proteins are encoded by a multigene family with members that are differentially expressed in various tissues and organs at distinct developmental stages. RBOHs have critical roles at several stages of nodulation: in the early signaling pathway triggered by nodulation factors in the root hairs, during both the progression of infection threads and nodule ontogeny, and in nitrogen fixation and senescence. Data from the literature along with the analysis conducted here imply that legumes use different RBOHs for different stages of nodulation; these RBOHs belong to the same phylogenetic subgroup, even though they are not strictly orthologous. Accordingly, the regulation of activity of a given $\mathrm{RBOH}$ during the nodulation process probably varies among legumes.
\end{abstract}

Keywords: legume nodulation; RBOHs; ROS; symbiotic signaling

\section{Introduction}

The symbiotic association of legumes with gram-negative soil bacteria results in the formation of nodules, unique structures in which the bacteria fix atmospheric nitrogen. These bacteria belong to various genera, including Rhizobium, Bradyrhizobium, Mesorhizobium, Sinorhizobium, and Azorhizobium. The symbiotic interaction is initiated in the rhizosphere with an exchange of chemical signals between the macrosymbiont and microsymbiont. The roots of leguminous plants secrete phenolic compounds, mainly (iso)flavonoids, and in response, the bacteria synthesize and secrete lipochitooligosaccharides known as nodulation (Nod) factors [1]. After the Nod factors are specifically recognized by receptors in the root hair cells of the legume, complex molecular and cellular responses initiate bacterial infection via the formation of an infection thread, a tubular structure formed by the plant through which the bacteria enter the root cortex. Simultaneously, a nodule primordium develops in the root cortex, triggering de novo cell division. In the early stages of the symbiosis, an upregulation of various plant genes occurs, among them the so-called early nodulins that participate in the development of the nodule primordium. Once the root hair cells have been infected by rhizobia, the rhizobia migrate through the infection thread to the base of the root hair cells and to the root cortex, where they are released from the infection thread and become enclosed by the host membrane to form a bacteria-containing vesicle called the symbiosome. In the symbiosome, the rhizobia differentiate into bacteroids and ultimately fix nitrogen [2]. 
Nodules can be indeterminate or determinate, differing in morphology and developmental programs. Legumes from the inverted repeat-lacking clade (e.g., Medicago sativa L., Pisum sativum L., and Vicia faba L.) develop indeterminate nodules, which have a persistent apical meristem and comprise different zones: the meristematic zone, infection zone, interzone, and nitrogen-fixing zone [3]. Phaseolus vulgaris L. and Glycine max (L.) Merr., considered tropical legumes, develop determinate nodules in which no focal meristem is evident; similarly, more temperate legume species such as Lotus japonicus L. form determinate nodules [4].

Reactive oxygen species (ROS) originating from the activity of respiratory burst oxidase homologs (RBOHs), called NADPH (NOX) oxidases in mammals, are generated in specific root tissues at different time points during establishment of the legume-rhizobia symbiosis [5]. RBOHs are plasma membrane proteins that catalyze the reduction of oxygen to generate superoxide anions utilizing the reducing power of NADPH. These proteins are approximately $100 \mathrm{kD}$ and possess six transmembrane regions. The third and fifth transmembrane domains coordinate a heme group through four histidine residues. Flavin and NADPH binding motifs are situated at the carboxy terminus, while the amino terminus contains regulatory sequences and two EF-hand motifs [6,7]. RBOH-mediated ROS production is stimulated when calcium ions interact with the EF-hand motifs, and phosphorylation is a synergistic key player. The activity of these enzymes is modulated at the amino terminus by protein kinases, calcium-dependent protein kinases, nitric oxide, and complexes between protein kinases and calcineurin B-like calcium sensors 1 and 9 [8].

In legumes, the Rboh genes encompass a large family, the members of which are differentially expressed in different tissues and organs at distinct developmental phases [5,9-11]. These enzymes have important roles at various stages of nodulation, such as in the signaling pathway triggered by Nod factors in the root hairs, in the advancement of the infection thread, in nodule ontogeny, in nitrogen fixation, and in senescence of the nodules. Here, we analyzed the role of Rboh genes in nodulation, focusing on their patterns of expression and their phylogenetic relationships in legumes, based on available genome sequences.

\section{RBOH Functions: From Nod Factor Perception to Rhizobial Infection and Nodule Development}

\subsection{ROS in the Early Signaling Pathway}

The process of the legume-rhizobia symbiosis can be divided into well-defined steps, in which morphological, cellular, and physiological changes occur in root cells. Data obtained during several decades of research by various groups allow sequential analysis of ROS levels and the expression of Rboh genes throughout nodulation. The transient ROS production observed in the apical region of $P$. vulgaris root hairs, within seconds of Nod factor perception, constitutes the fastest response recorded to date [12] (Figure 1). In G. max, a related response by ROS production was reported $2 \mathrm{~min}$ after rhizobial inoculation, both in the apical and perinuclear region of the root hair cells $[13,14]$. The specificity of these oxidative bursts indicates their central role in the early symbiotic signaling pathway [5]. Modulation of Rboh expression at this stage has not been reported, and considering the rapid nature of this response, variations at the transcriptional level are unlikely; however, a 3.9-fold increase in NADPH oxidase activity was detected in a microsomal fraction of P. sativum roots $5 \mathrm{~min}$ after inoculation with Rhizobium [15], a response that can be linked to an increase in calcium flux at the tip of the responding root hair cell $[16,17]$. Calcium is a major regulator of $\mathrm{RBOH}$ activity that binds to the EF-hand motifs at the amino terminus [18]; however, these enzymes can also be modulated by interaction with small GTPases of the Rho family [19]. In L. japonicus, ROP6 interacts in planta with Nod factor receptor 5 (NFR5) at the plasma membrane [20]. In M. truncatula, Nod factor induces expression of ROP10, which interacts with the kinase domain of the Nod factor receptor NFP in a GTP-dependent manner [21]. These reports demonstrate that ROP GTPases participate in the legume-rhizobia symbiosis, and are candidate regulators of RBOHs. 


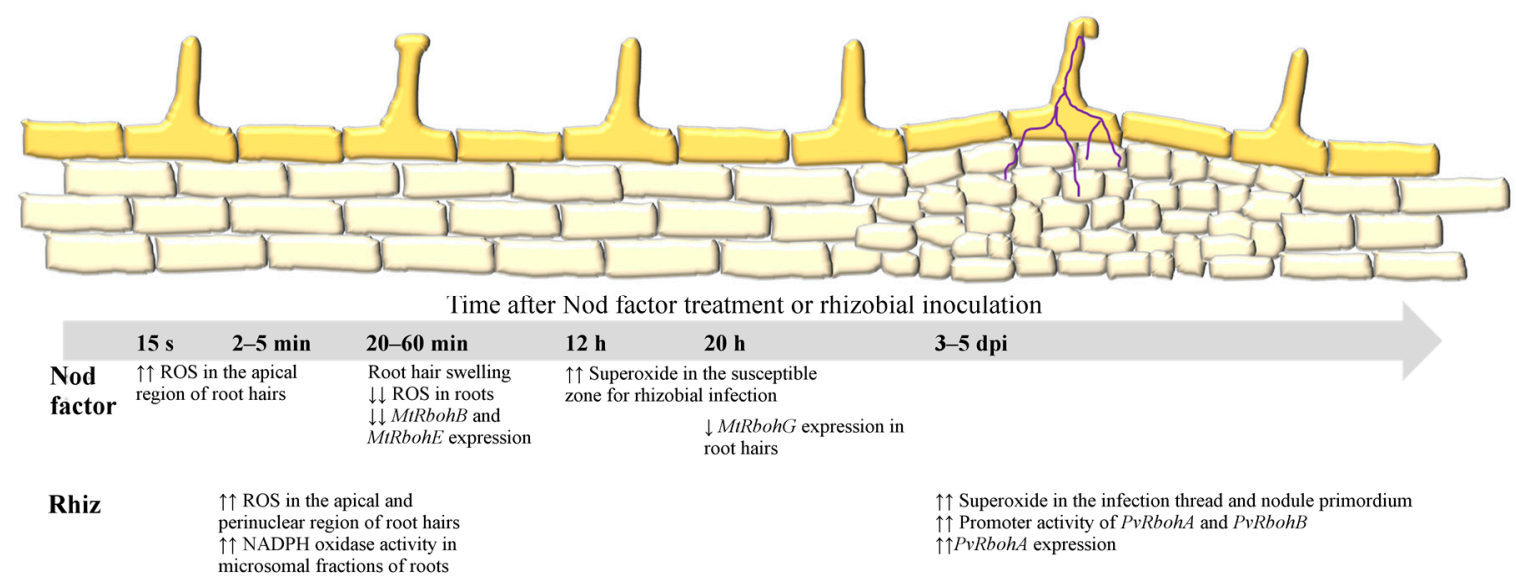

Figure 1. ROS levels and Rboh expression after Nod factor perception, rhizobial infection, and nodule primordium formation. The early stages of nodulation are illustrated along with the changes in ROS levels and Rboh expression after Nod factor treatment or rhizobial (Rhiz) inoculation. The purple line indicates the infection thread progression. The arrows indicate an increase ( $\uparrow$ ) and a decrease $(\downarrow)$ of ROS levels and Rboh expression.

In a subsequent stage of nodulation, 20-30 min after Nod factor addition, hydrogen peroxide generation is suppressed in $M$. truncatula roots. This response is apparently symbiosis-specific, since ROS levels are not affected in the $n f p$ mutant background, which shows no measurable response to Nod factor [17]. Low levels of ROS remain for $1 \mathrm{~h}$ after Nod factor treatment in $M$. truncatula roots, which parallels with the downregulation of two MtRbohs (MtRbohB and MtRbohE) that cause root hair swelling [22] (Figure 1). The modulation of ROS levels is highly dynamic, since superoxide accumulates to high levels in the region susceptible to rhizobial infection $12 \mathrm{~h}$ after incubation of $M$. truncatula roots with Nod factor [23] (Figure 1). At $20 \mathrm{~h}$ after Nod factor treatment, eight Rboh genes (MtRbohA, MtRbohB, MtRbohD, MtRbohE, MtRbohF, MtRbohG, MtRbohH, and MtRbohI) are expressed in M. truncatula root hairs, with $M t R b o h G$ being slightly downregulated [24].

\subsection{RBOHs Modulate Infection Thread Growth and Nodule Organogenesis}

Superoxide accumulates to high levels in the infection thread, the tubular structure employed by rhizobia to invade the root hair cell [25]. PvRbohA and PvRbohB expression is strongly upregulated in P. vulgaris root hairs $[10,26]$. Using translational fusions to yellow fluorescent protein as a reporter, these enzymes were detected in infection pockets of P. vulgaris root hairs. PvRBOHB is mainly restricted to the sites of infection thread progression [5], while PvRBOHA is localized throughout the infection thread and at the base of the root hair cell [26]. The role played by these oxidases in P. vulgaris infection threads is likely comparable to that of $\mathrm{RBOH}$ members in Arabidopsis thaliana (L.) Heynh., as a mediator of cell wall loosening and strengthening during the polar growth of root hairs and pollen tubes [27,28]. Remodeling of cell wall flexibility is key for rhizobial infection and occurs at the base of the root hair and at the growth pole of the infection thread, the respective sites where PvRBOHA and $P v R B O H B$ are located. The crucial role of these oxidases during infection thread advancement was demonstrated by RNAi-mediated gene silencing in transgenic P. vulgaris roots. In both PvRbohA-RNAi and PvRbohB-RNAi plants, infection threads are aborted at the base of the root hair $[10,26]$. However, the number of infection events per root is not affected in PvRbohB-RNAi roots, while a significant reduction in this process can be observed in PvRbohA-RNAi plants, indicating non-overlapping roles of these genes during rhizobial infection.

A similar scenario was described in A. thaliana, where both AtRBOHH and AtRBOHJ are located in the membrane of the pollen tube, but with different distribution patterns [29]. A recent report from our group shows that rhizobial infection, ROS production, and $P v R b o h B$ expression are reduced in P. vulgaris transgenic roots after silencing of annexin 1, a homolog of Atann1. In A. thaliana, Ann1 
promotes $\mathrm{Ca}^{2+}$ influx through the plasma membrane in response to salinity [30]. In L. japonicus, infection thread progression is also severely affected in LjROP6-RNAi plants, leading to fewer nodules, a phenotype that resembles PvRbohA-RNAi or PvRbohB-RNAi plants in P. vulgaris [20]. Likewise, rhizobial infection is impaired in M. truncatula ROP9-RNAi plants. Both ROS levels and MtRbohB expression are suppressed in $M t R O P 9$-silenced plants after rhizobial inoculation, showing a direct interplay with $\mathrm{RBOH}$ in nodulation [31].

In parallel with rhizobial infection, nodule primordia develop in the cortex cells, where superoxide is produced at high levels $[23,25]$. PvRbohA and $P v R b o h B$ are expressed in the vascular bundles of the nodule primordium; nevertheless, only the $P v R b o h B$ promoter is active in the dividing cortical cells $[10,26]$. In $M$. truncatula, the promoter activity of $M t R b o h E, M t R b o h F$, and $M t R b o h G$ is mainly associated with the vascular bundles of the nodules, whereas $M t R b o h B$ promoter activity is associated with the meristem [9]. These observations indicate that Rboh genes are recruited at different regions of the developing organ. In plants, diverse growth and developmental processes are coordinated by the interplay of ROS and phytohormones [32]. For instance, AtRBOHD-mediated ROS production is required for auxin-dependent cell division during lateral root development in A. thaliana [33]. In the legume-rhizobia symbiosis, auxins are produced in rhizobia-infected root hairs and during nodule primordium formation [34,35], which is associated with the induction of genes involved in auxin metabolism [26,35]. The upregulation of cytokinin- and auxin-related genes is repressed in PvRbohB-RNAi roots after rhizobial inoculation [36], supporting the close connection between ROS and hormones in the legume-rhizobia symbiosis.

\subsection{Phylogenetic Distribution and Expression of Rboh Genes of Legumes in Nodules}

In legumes, as in other plant species, Rbohs constitute gene families of variable sizes, with specific spatial and temporal expression patterns in tissues and organs $[5,9,10,37]$. In previous studies, incomplete genome information in M. truncatula and L. japonicus led to the partial identification of Rboh genes [9,10]. A more recent search of available genome information [38,39] prompted us to determine the composition of the Rboh family in these legumes. L. japonicus, like P. vulgaris, has nine Rbohs, while in M. truncatula the family has ten members. The phylogenetic reconstruction of these oxidases reveals that, in most cases, putative orthologs can be identified among these species (Figure 2). To date, only three legume Rboh genes have been functionally characterized throughout the different steps of nodulation: PvRbohA, PvRbohB, and MtRbohA [9-11,26]. MtRbohA was the first legume NADPH oxidase reportedly involved in nodulation and it is the most abundant Rboh transcript in $M$. truncatula nodules [9]. The first stages of the symbiotic process are not affected in MtRbohA-RNAi plants; however, nitrogen fixation is reduced [9]. In P. vulgaris, both PvRbohA and PvRbohB are important during rhizobial infection and nodule organogenesis $[10,26]$, although they are not direct orthologs of MtRbohA.

A study of RbohE during arbuscular mycorrhization in $M$. truncatula suggests a role for this gene in arbuscule accommodation within cortical cells [37]. Based on our phylogenetic data, MtRbohE is a putative ortholog of PvRbohA (Figure 2). However, these genes seem to have different functions, since rhizobial infection is aborted in PvRbohA-silenced roots [26], whereas nodulation is not affected in M. truncatula plants expressing an MtRbohE-RNAi construct [37]. Because the roles of few Rbohs have been evaluated in legume-rhizobia symbiosis, it is difficult to compare them. However, the availability of gene expression databases for M. truncatula [40], P. vulgaris [41], and L. japonicus [38] has facilitated studies of comparative expression. The expression of MtRbohs, PvRbohs, and LjRbohs in nitrogen-fixing nodules demonstrates remarkable differences in the Rboh families (Figure 3A-C). Both P. vulgaris and L. japonicus develop determinate nodules; however, in P. vulgaris, five members are abundantly transcribed in nodules (PvRbohA, PvRbohB, PvRbohC, PvRbohD, and PvRbohF), while in L. japonicus, only $L j R b o h E$ is highly expressed compared to the other members of this gene family (Figure $3 \mathrm{~A}, \mathrm{~B}$ ). However, in both L. japonicus and M. truncatula, Rboh genes exhibit changes in expression at different stages of nodulation (Figure 3D,E). In M. truncatula, L. japonicus, and P. vulgaris, the Rboh isoforms 
highly expressed in nodules are located in the same subclade of the phylogenetic tree (Figure 2, shaded clade, and Figure 3A-C). Likewise, in the recently assembled nodule transcriptomes of P. sativum, Galega orientalis Lam., Astragalus canadensis L., Onobrychis viciifolia Scop., and Glycyrrhiza uralensis Fisch. [42,43], the most highly expressed Rbohs are clustered in this subclade (Figure 2, shaded clade). These legumes, like M. truncatula, belong to the inverted repeat-lacking clade in which nodules are indeterminate [30] and form a meristem at the tip, establishing a developmental gradient across each nodule. These developmental regions are classified into different zones, with the meristematic zone being the youngest region and the nitrogen-fixing zone the oldest, each showing particular expression profiles [31]. MtRbohC, MtRbohD, MtRbohE, MtRbohF, and MtRbohG are preferentially expressed in the meristematic region of $M$. truncatula nodules (ZI in Figure 3F). Therefore, these oxidases may be involved in maintaining mitotic activity in the nodule. For instance, ROS, particularly $\mathrm{H}_{2} \mathrm{O}_{2}$ and superoxide, regulate cell proliferation and cell fate determination [44]. Accumulating evidence demonstrates the key role played by ROS in cell division and root growth. The decreased epidermal root cell size phenotype of the nitrate transporter mutant latd of $M$. truncatula is due to high ROS levels and $M t R b o h C$ expression, and reverts to wild-type by $M t R b o h C$ silencing or abscisic acid treatment [45]. During lateral root emergence, the PvRbohB promoter is expressed, and the lateral root density is reduced when this NADPH oxidase is silenced [46]. Similarly, disrupting or enhancing RBOH activity influences the development and emergence of lateral roots in A. thaliana [33].

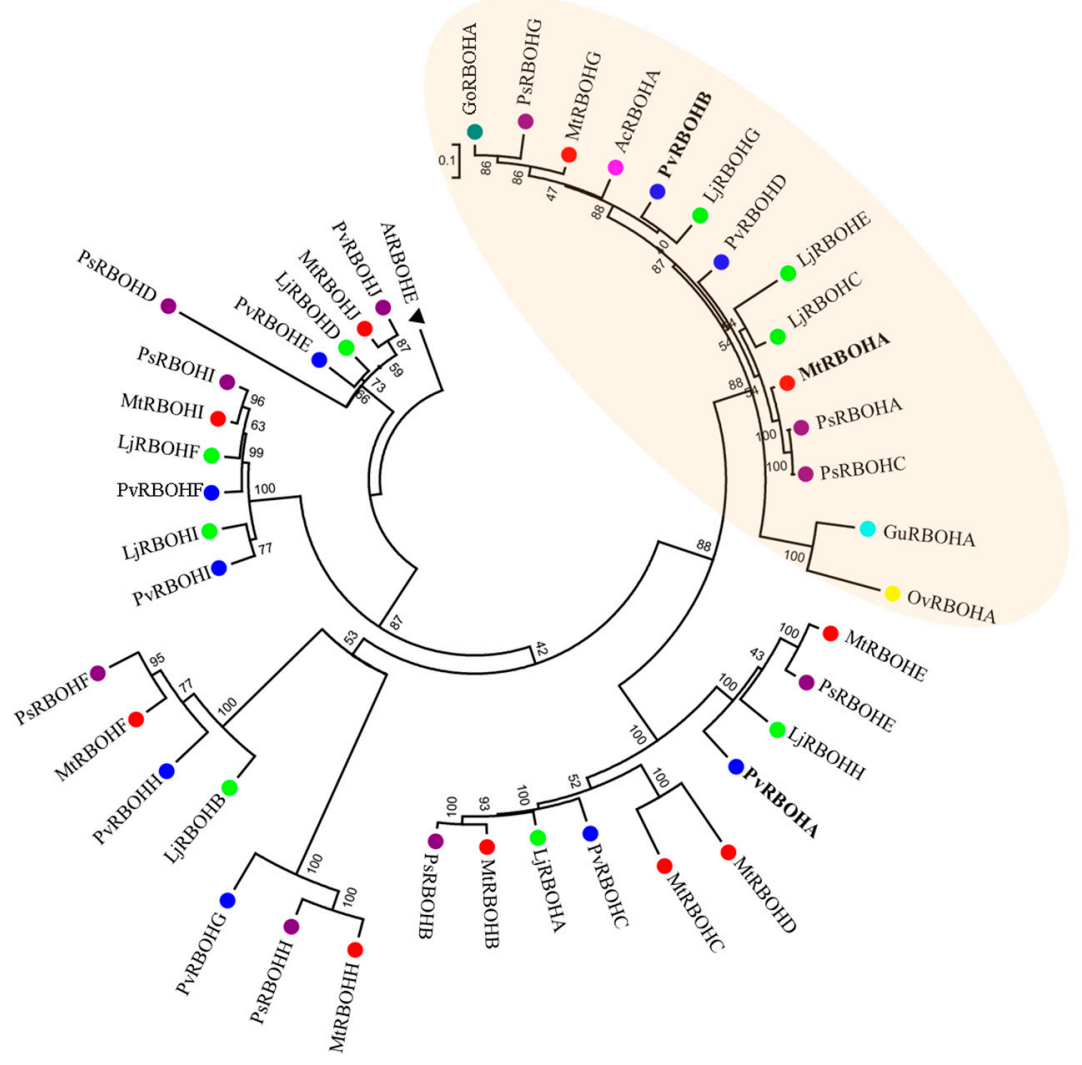

Figure 2. Phylogenetic distribution of RBOHs in legumes. Phylogenetic relationship of RBOHs from M. truncatula (red), P. vulgaris (blue), L. japonicus (green), P. sativum (purple), G. orientalis (dark cyan), A. canadensis (pink), O. viciifolia (olive), and G. uralensis (cyan). The phylogenetic tree was constructed using the maximum likelihood method based on the JTT matrix-based model using MEGA7 software. The tree was drawn to scale, with branch lengths measured by the number of substitutions per site. Percentages of bootstrap values obtained from 1000 trials are shown at the nodes. The tree was rooted with the AtRBOHE sequence (black triangle). The genes functionally tested in nodulation are in bold. Annotations of the sequences are in Supplementary Table S1. The shaded oval highlights the clade with $\mathrm{RBOH}$ isoforms highly expressed in nodules. 
A

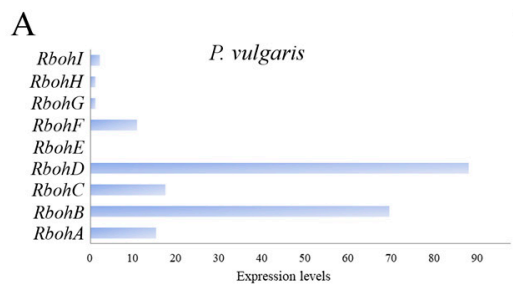

$\mathrm{D}$

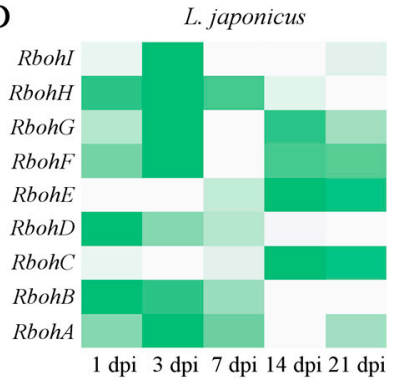

B
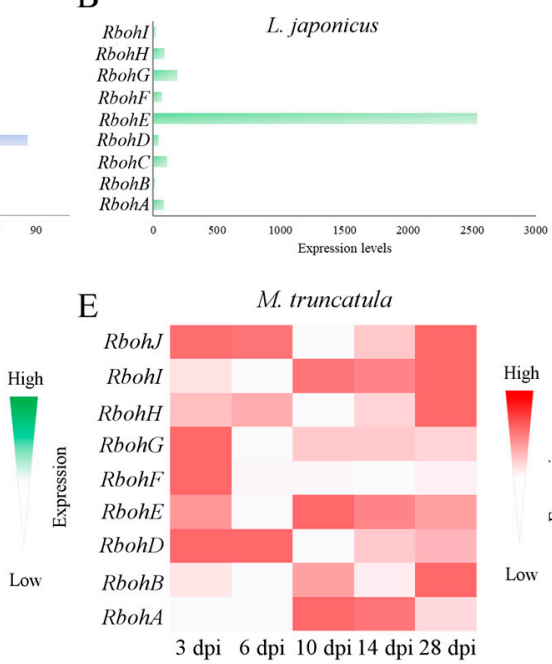

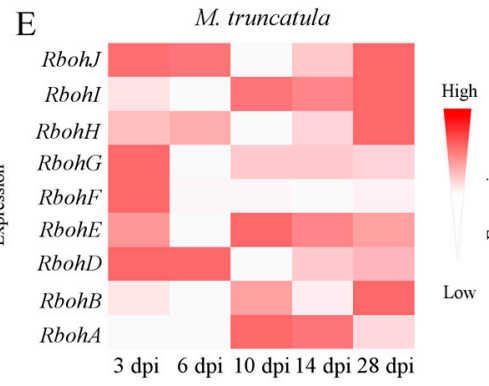

$\mathrm{C}$

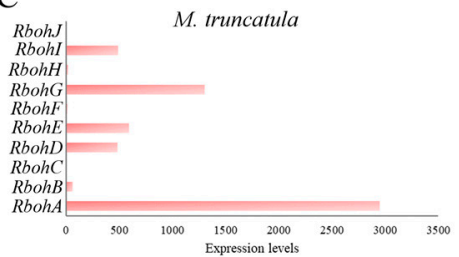

$\mathrm{F}$

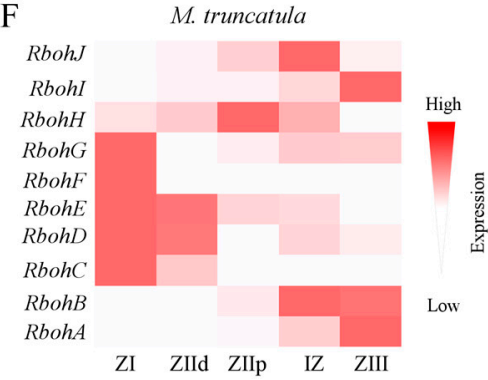

Figure 3. Expression profiles of nodule-expressed Rbohs in legumes. (A-C), Expression levels of Rbohs in nodules of P. vulgaris (A), L. japonicus (B), and M. truncatula (C) at $21 \mathrm{dpi}(\mathbf{A}, \mathbf{B})$ and $28 \mathrm{dpi}$ (C) $[38,40,41]$. Heatmap showing expression of Rbohs from L. japonicus (D) and M. truncatula (E) in roots (1-7 dpi) and nodules (10-28 dpi) following inoculation with Rhizobium. Heatmap showing $M t$ Rboh expression in different zones of $M$. truncatula nodules at 15 dpi with Sinorhizobium meliloti (F). ZI, meristematic zone; ZII, infection zone; IZ, interzone; and ZIII, nitrogen-fixing zone [3].

In the region where rhizobia are released from the infection threads of $M$. truncatula nodules (ZIIp), MtRbohH is most strongly expressed, while transcripts of MtRbohB and MtRbohJ are mainly found in the interzone (Figure 3F). As shown by Marino et al. [9], MtRbohA is particularly expressed in the nitrogen-fixing zone and is required for proper nodule functioning. However, $M t R b o h A$ is not the isoform preferentially expressed in the nitrogen-fixing zone (ZIII), since MtRbohI and MtRbohB transcripts are abundant in this zone (Figure 3F). A recent report [47] revealed the great complexity of Rboh regulation in nodule functioning. $M t R b o h B, M t R b o h C$, and $M t R b o h D$ are major players in the exacerbated plant defense response of the nad1 M. truncatula mutant, in which innate immunity is excessively activated. Mutation of these genes prevents nodule necrosis, and effective nodules are restored in the nad1 mutant background.

\section{Conclusions}

RBOHs have been shown to function throughout the nodulation process in several legumes that develop indeterminate and determinate nodules. For distinct steps in nodulation, legumes use different $\mathrm{RBOHs}$ that belong to the same phylogenetic subgroup, although they are not strictly orthologous sequences. The regulation of activity of a given $\mathrm{RBOH}$ during nodulation probably varies between legumes, supporting the idea that determinate and indeterminate nodules might have different ROS requirements. Functional characterization of additional legume Rboh genes is necessary to gain insight into the role of these genes in the legume-rhizobia symbiosis. New approaches such as CRISPR/Cas gene editing provide opportunities to engineer individual or multiple genes in efforts to more precisely define the role of Rbohs during mutualistic interactions.

Supplementary Materials: The following are available online at http:/ /www.mdpi.com/2077-0472/8/11/179/s1, Table S1: Sequence and annotation of the RBOH homologs used for the phylogenetic analysis.

Author Contributions: J.M. carried out the studies, collected and processed data. C.F.-G. carried out the phylogenetic analysis. C.Q. and J.M. discussed the data and wrote the manuscript.

Funding: This research was partially funded by DGAPA-UNAM grant number IN204115.

Acknowledgments: The authors would like to acknowledge Luis Cárdenas for critically reading the manuscript. C.F.-G. is a recipient of a postdoctoral DGAPA-UNAM fellowship. 
Conflicts of Interest: The authors declare no conflict of interest.

\section{References}

1. Oldroyd, G.E.D.; Murray, J.D.; Poole, P.S.; Downie, J.A. The rules of engagement in the legume-rhizobial symbiosis. Annu. Rev. Genet. 2011, 45, 119-144. [CrossRef] [PubMed]

2. Downie, J.A. Legume nodulation. Curr. Biol. 2014, 24, R184-R190. [CrossRef] [PubMed]

3. Kondorosi, E.; Mergaert, P.; Kereszt, A. A paradigm for endosymbiotic life: Cell differentiation of Rhizobium bacteria provoked by host plant factors. Annu. Rev. Microbiol. 2013, 67, 611-628. [CrossRef] [PubMed]

4. Ferguson, B.J.; Indrasumunar, A.; Hayashi, S.; Lin, M.-H.; Lin, Y.-H.; Reid, D.E.; Gresshoff, P.M. Molecular analysis of legume nodule development and autoregulation. J. Integr. Plant Biol. 2010, 52, 61-76. [CrossRef] [PubMed]

5. Montiel, J.; Arthikala, M.K.; Cárdenas, L.; Quinto, C. Legume NADPH oxidases have crucial roles at different stages of nodulation. Int. J. Mol. Sci. 2016, 17, 680. [CrossRef] [PubMed]

6. Torres, M.A.; Dangl, J.L. Functions of the respiratory burst oxidase in biotic interactions, abiotic stress and development. Curr. Opin. Plant Biol. 2005, 8, 397-403. [CrossRef] [PubMed]

7. Glyan'ko, A.K.; Ischenko, A.A. Structural and functional characteristics of plant NADPH oxidase: A review. Appl. Biochem. Microbiol. 2010, 46, 463-471. [CrossRef]

8. Kaur, G.; Sharma, A.; Guruprasad, K.; Pati, P.K. Versatile roles of plant NADPH oxidases and emerging concepts. Biotechnol. Adv. 2014, 32, 551-563. [CrossRef] [PubMed]

9. Marino, D.; Andrio, E.; Danchin, E.G.J.; Oger, E.; Gucciardo, S.; Lambert, A.; Puppo, A.; Pauly, N. A Medicago truncatula NADPH oxidase is involved in symbiotic nodule functioning. New Phytol. 2011, 189, 580-592. [CrossRef] [PubMed]

10. Montiel, J.; Nava, N.; Cárdenas, L.; Sánchez-López, R.; Arthikala, M.K.; Santana, O.; Sánchez, F.; Quinto, C. A Phaseolus vulgaris NADPH oxidase gene is required for root infection by Rhizobia. Plant Cell Physiol. 2012, 53, 1751-1767. [CrossRef] [PubMed]

11. Arthikala, M.K.; Sánchez-López, R.; Nava, N.; Santana, O.; Cárdenas, L.; Quinto, C. RbohB, a Phaseolus vulgaris NADPH oxidase gene, enhances symbiosome number, bacteroid size, and nitrogen fixation in nodules and impairs mycorrhizal colonization. New Phytol. 2014, 202, 886-900. [CrossRef] [PubMed]

12. Cárdenas, L.; Martínez, A.; Sánchez, F.; Quinto, C. Fast, transient and specific intracellular ROS changes in living root hair cells responding to Nod factors (NFs). Plant J. 2008, 56, 802-813. [CrossRef] [PubMed]

13. Muñoz, N.; Robert, G.; Melchiorre, M.; Racca, R.; Lascano, R. Saline and osmotic stress differentially affects apoplastic and intracellular reactive oxygen species production, curling and death of root hair during Glycine max L.-Bradyrhizobium japonicum interaction. Environ. Exp. Bot. 2012, 78, 76-83. [CrossRef]

14. Robert, G.; Muñoz, N.; Alvarado-Affantranger, X.; Saavedra, L.; Davidenco, V.; Rodríguez-Kessler, M.; Estrada-Navarrete, G.; Sánchez, F.; Lascano, R. Phosphatidylinositol 3-kinase function at very early symbiont perception: A local nodulation control under stress conditions? J. Exp. Bot. 2018, 69, 2037-2048. [CrossRef] [PubMed]

15. Glyan'ko, A.K.; Ischenko, A.A. Influence of rhizobial (Rhizobium leguminosarum) inoculation and calcium ions on the NADPH oxidase activity in roots of etiolated pea (Pisum sativum L.) seedlings. Appl. Biochem. Microbiol. 2013, 49, 215-219. [CrossRef]

16. Cárdenas, L.; Feijo, J.A.; Kunkel, J.G.; Sánchez, F.; Holdaway-Clarke, T.; Hepler, P.K.; Quinto, C. Rhizobium Nod factors induce increases in intracellular free calcium and extracellular calcium influxes in bean root hairs. Plant J. 1999, 19, 347-352. [CrossRef] [PubMed]

17. Shaw, S.L.; Long, S.R. Nod factor inhibition of reactive oxygen efflux in a host legume. Plant Physiol. 2003, 132, 2196-2204. [CrossRef] [PubMed]

18. Kobayashi, M.; Ohura, I.; Kawakita, K.; Yokota, N.; Fujiwara, M.; Shimamoto, K.; Doke, N.; Yoshioka, H. Calcium-dependent protein kinases regulate the production of reactive oxygen species by potato NADPH oxidase. Plant Cell 2007, 19, 1065-1080. [CrossRef] [PubMed]

19. Wong, H.L.; Pinontoan, R.; Hayashi, K.; Tabata, R.; Yaeno, T.; Hasegawa, K.; Kojima, C.; Yoshioka, H.; Iba, K.; Kawasaki, T.; et al. Regulation of rice NADPH oxidase by binding of Rac GTPase to its $\mathrm{N}$-terminal extension. Plant Cell 2007, 19, 4022-4034. [CrossRef] [PubMed] 
20. Ke, D.; Fang, Q.; Chen, C.; Zhu, H.; Chen, T.; Chang, X.; Yuan, S.; Kang, H.; Ma, L.; Hong, Z.; et al. The small GTPase ROP6 interacts with NFR5 and is involved in nodule formation in Lotus japonicus. Plant Physiol. 2012, 159, 131-143. [CrossRef] [PubMed]

21. Lei, M.-J.; Wang, Q.; Li, X.; Chen, A.; Luo, L.; Xie, Y.; Li, G.; Luo, D.; Mysore, K.S.; Wen, J.; et al. The small GTPase ROP10 of Medicago truncatula is required for both tip growth of root hairs and nod factor-induced root hair deformation. Plant Cell 2015, 27, 806-822. [CrossRef] [PubMed]

22. Lohar, D.P.; Haridas, S.; Gantt, J.S.; VandenBosch, K.A. A transient decrease in reactive oxygen species in roots leads to root hair deformation in the legume-rhizobia symbiosis. New Phytol. 2007, 173, $39-49$. [CrossRef] [PubMed]

23. Ramu, S.K.; Peng, H.; Cook, D.R. Nod factor induction of reactive oxygen species production is correlated with expression of the early nodulin gene rip1 in Medicago truncatula. Mol. Plant-Microbe Interact. 2002, 15, 522-528. [CrossRef] [PubMed]

24. Damiani, I.; Drain, A.; Guichard, M.; Balzergue, S.; Boscari, A.; Boyer, J.-C.; Brunaud, V.; Cottaz, S.; Rancurel, C.; Da Rocha, M.; et al. Nod factor effects on root hair-specific transcriptome of Medicago truncatula: Focus on plasma membrane transport systems and reactive oxygen species networks. Front. Plant Sci. 2016, 7, 794. [CrossRef] [PubMed]

25. Santos, R.; Hérouart, D.; Sigaud, S.; Touati, D.; Puppo, A. Oxidative burst in alfalfa-Sinorhizobium meliloti symbiotic interaction. Mol. Plant-Microbe Interact. 2001, 14, 86-89. [CrossRef] [PubMed]

26. Arthikala, M.-K.; Montiel, J.; Sánchez-López, R.; Nava, N.; Cárdenas, L.; Quinto, C. Respiratory burst oxidase homolog gene $\mathrm{A}$ is crucial for Rhizobium infection and nodule maturation and function in common bean. Front. Plant Sci. 2017, 8, 2003. [CrossRef] [PubMed]

27. Foreman, J.; Demidchik, V.; Bothwell, J.H.F.; Mylona, P.; Miedema, H.; Torres, M.A.; Linstead, P.; Costa, S.; Brownlee, C.; Jones, J.D.G.; et al. Reactive oxygen species produced by NADPH oxidase regulate plant cell growth. Nature 2003, 422, 442-446. [CrossRef] [PubMed]

28. Potocký, M.; Jones, M.A.; Bezvoda, R.; Smirnoff, N.; Zarsky, V. Reactive oxygen species produced by NADPH oxidase are involved in pollen tube growth. New Phytol. 2007, 174, 742-751. [CrossRef] [PubMed]

29. Lassig, R.; Gutermuth, T.; Bey, T.D.; Konrad, K.R.; Romeis, T. Pollen tube NAD(P)H oxidases act as a speed control to dampen growth rate oscillations during polarized cell growth. Plant J. 2014, 78, 94-106. [CrossRef] [PubMed]

30. Laohavisit, A.; Richards, S.L.; Shabala, L.; Chen, C.; Colaco, R.D.D.R.; Swarbreck, S.M.; Shaw, E.; Dark, A.; Shabala, S.; Shang, Z.; et al. Salinity-induced calcium signaling and root adaptation in Arabidopsis Require the calcium regulatory protein annexin1. Plant Physiol. 2013, 163, 253-262. [CrossRef] [PubMed]

31. Kiirika, L.M.; Bergmann, H.F.; Schikowsky, C.; Wimmer, D.; Korte, J.; Schmitz, U.; Niehaus, K.; Colditz, F. Silencing of the Rac1 GTPase MtROP9 in Medicago truncatula stimulates early mycorrhizal and oomycete root colonizations but negatively affects rhizobial infection. Plant Physiol. 2012, 159, 501-516. [CrossRef] [PubMed]

32. Tognetti, V.B.; Bielach, A.; Hrtyan, M. Redox regulation at the site of primary growth: Auxin, cytokinin and ROS crosstalk. Plant Cell Environ. 2017, 40, 2586-2605. [CrossRef] [PubMed]

33. Orman-Ligeza, B.; Parizot, B.; de Rycke, R.; Fernandez, A.; Himschoot, E.; Van Breusegem, F.; Bennett, M.J.; Périlleux, C.; Beeckman, T.; Draye, X. RBOH-mediated ROS production facilitates lateral root emergence in Arabidopsis. Development 2016, 143, 3328-3339. [CrossRef] [PubMed]

34. Suzaki, T.; Yano, K.; Ito, M.; Umehara, Y.; Suganuma, N.; Kawaguchi, M. Positive and negative regulation of cortical cell division during root nodule development in Lotus japonicus is accompanied by auxin response. Development 2012, 139, 3997-4006. [CrossRef] [PubMed]

35. Nadzieja, M.; Kelly, S.; Stougaard, J.; Reid, D. Epidermal auxin biosynthesis facilitates rhizobial infection in Lotus japonicus. Plant J. 2018, 95, 101-111. [CrossRef] [PubMed]

36. Fonseca-García, C.; Zayas, A.E.; Montiel, J.; Nava, N.; Sánchez, F.; Quinto, C. Transcriptome reprogramming by modulating the expression of the NADPH oxidase gene RbohB in Phaseolus vulgaris roots after rhizobia and Rhizophagus irregularis inoculation. Plant Mol. Biol. 2018. submitted.

37. Belmondo, S.; Calcagno, C.; Genre, A.; Puppo, A.; Pauly, N.; Lanfranco, L. The Medicago truncatula MtRbohE gene is activated in arbusculated cells and is involved in root cortex colonization. Planta 2016, 243, 251-262. [CrossRef] [PubMed] 
38. Mun, T.; Bachmann, A.; Gupta, V.; Stougaard, J.; Andersen, S.U. Lotus base: An integrated information portal for the model legume Lotus japonicus. Sci. Rep. 2016, 6, 39447. [CrossRef] [PubMed]

39. Goodstein, D.M.; Shu, S.; Howson, R.; Neupane, R.; Hayes, R.D.; Fazo, J.; Mitros, T.; Dirks, W.; Hellsten, U.; Putnam, N.; et al. Phytozome: A comparative platform for green plant genomics. Nucleic Acids Res. 2012, 40, D1178-D1186. [CrossRef] [PubMed]

40. Benedito, V.A.; Torres-Jerez, I.; Murray, J.D.; Andriankaja, A.; Allen, S.; Kakar, K.; Wandrey, M.; Verdier, J.; Zuber, H.; Ott, T.; et al. A gene expression atlas of the model legume Medicago truncatula. Plant J. 2008, 55, 504-513. [CrossRef] [PubMed]

41. O'Rourke, J.A.; Iniguez, L.P.; Fu, F.; Bucciarelli, B.; Miller, S.S.; Jackson, S.A.; Mcclean, P.E.; Li, J.; Dai, X.; Zhao, P.X.; et al. An RNA-Seq based gene expression atlas of the common bean An RNA-Seq based gene expression atlas of the common bean. BMC Genom. 2014, 15, 866. [CrossRef] [PubMed]

42. Alves-Carvalho, S.; Aubert, G.; Carrère, S.; Cruaud, C.; Brochot, A.L.; Jacquin, F.; Klein, A.; Martin, C.; Boucherot, K.; Kreplak, J.; et al. Full-length de novo assembly of RNA-seq data in pea (Pisum sativum L.) provides a gene expression atlas and gives insights into root nodulation in this species. Plant J. 2015, 84, 1-19. [CrossRef] [PubMed]

43. Montiel, J.; Downie, J.A.; Farkas, A.; Bihari, P.; Herczeg, R.; Bálint, B.; Mergaert, P.; Kereszt, A.; Kondorosi, É. Morphotype of bacteroids in different legumes correlates with the number and type of symbiotic NCR peptides. Proc. Natl. Acad. Sci. USA 2017, 114, 5041-5046. [CrossRef] [PubMed]

44. Burch, P.M.; Heintz, N.H. Redox regulation of cell-cycle re-entry: Cyclin D1 as a primary target for the mitogenic effects of reactive oxygen and nitrogen species. Antioxid. Redox Signal. 2005, 7, 75-141. [CrossRef] [PubMed]

45. Zhang, C.; Bousquet, A.; Harris, J.M. Abscisic acid and lateral root organ defective/numerous infections and polyphenolics modulate root elongation via reactive oxygen species in Medicago truncatula. Plant Physiol. 2014, 166, 644-658. [CrossRef] [PubMed]

46. Montiel, J.; Arthikala, M.; Quinto, C. Phaseolus vulgaris RbohB functions in lateral root development. Plant Signal. Behav. 2013, 8, 144-146. [CrossRef] [PubMed]

47. Yu, H.; Xiao, A.; Dong, R.; Fan, Y.; Zhang, X.; Liu, C.; Wang, C.; Zhu, H.; Duanmu, D.; Cao, Y.; et al. Suppression of innate immunity mediated by the CDPK-Rboh complex is required for rhizobial colonization in Medicago truncatula nodules. New Phytol. 2018, 220, 425-434. [CrossRef] [PubMed] 